\title{
ЭТИОПАТОГЕНЕТИЧЕСКИЕ АСПЕКТЫ ПРЕЖДЕВРЕМЕННОГО ИСТОЩЕНИЯ ЯИЧНИКОВ
}

\author{
Фахрутдинова С.С., Шариксиева М.А., Хайдарова Ф.А.
}

Республиканский Специализированный Научно-Практический Медицинский Центр Эндокринологии имени академика Е.Х.Туракулова, Ташкент, узбекистан

АКТУАльность: в настоящее время в мире преждевременное истощение яичников (ПИЯ) считается актуальной медико-социальной проблемой. Особое внимание уделяется исследованиям по определению заболеваний женщин детородного возраста, совершенствованию методов ранней диагностики, лечения и профилактики на основе иммуногенетических исследований. В этой области приоритетными направлениями научных исследований остаются выявление гетерогенных причин ПИЯ, генетических, ферментативных, аутоиммунных, инфекционно-токсических, ятрогенных и психологических факторов, определение изменений их биохимических и иммунологических показателей. Раннее предопределение генных мутаций с целью профилактики является наиболее актуальной проблемой специалистов в этой области.

ЦЕЛЬ: определить клинические и генетические маркеры при прогнозировании преждевременном истощении яичников у женщин Узбекистана.

Объект исследования: скрининг данных 3421 женщины фертильного возраста и клиническое, лабораторное, медико-генетическое обследование 85 пациенток с ПИЯ.

PЕзУЛЬтАТЫ: среди 3421 анкеты была выявлена группа из 454 женщин с аменореей в возрасте до 40 лет (13,3\% от общего числа обследованных женщин и 58,3\% от числа женщин с аменореей). У 85 жен-

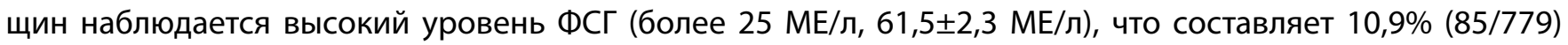
от общего числа женщин с аменореей и 2,5\% от общего числа респондентов (85/3421). Количество женщины с ПИЯ в возрасте до 20 лет составляет 9,1\%, а женщин старше 36 лет - 34,1\%. При анализе характера репродуктивной функции выяснилось, что у 35 (41,2\%) из 85 пациентов с ПИЯ в анамнезе были роды, у 12 (14,1\%) были аборты. Из 85 пациентов с ПИЯ, у 13 (15,3\%) женщин было отмечено первичное бесплодие и у 12 (14,1\%) женщин - вторичное бесплодие. Средний уровень ЛГ и ФСГ у пациентов с ПИЯ был зна-

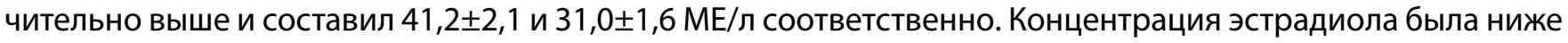
нормативных значений и составила 70,4 4,2 пг/мл. В молекулярно-генетическом исследовании было генотипировано 83 образца. Гомозиготная мутация A/A полиморфизма rs 6166 гена FSHR встречалась почти в 2 раза чаще в основной группе и составила 23,6\% против 10,7\%. При анализе полиморфизма rs 6165 гена FSHR выявлено 2-кратное увеличение частоты этого генотипа у пациентов основной группы (14,6\%) по сравнению с контрольной группой $(7,1 \%)$. В результате изучения генно-генетических взаимодействий аллельных вариантов полиморфизма rs6165 и rs6166 гена FSHR мы обнаружили, что сочетание функционально неблагоприятных генотипов полиморфизма rs 6165 + rs 6166 гена FSHR значительно увеличивает риск формирования отклонения $\left(\mathrm{X}^{2}=4,1 ; \mathrm{P}=0,04 ; \mathrm{OR}=3,7 ; 95 \% \mathrm{Cl} 0,98-14,05\right)$.

Выводы: частота встречаемости ПИЯ в Узбекистане составляет 2,5\%. Клинические и гормональные маркеры для прогнозирования ПИЯ - повышение уровня ФСГ выше 25 МЕ/л ( $r=0,61 ; \mathrm{P}<0,01)$, снижение значений эстрадиола ниже 75 пг/мл ( $r=0,47 ; \mathrm{P}<0,01)$, снижение количества антральных фолликулов (менее 6 шт.) при УЗИ ( $r=0,75 ; \mathrm{P}<0,01)$. В результате изучения генно-генетических взаимодействий аллельных вариантов полиморфизма rs6165 и rs6166 гена FSHR мы обнаружили, что сочетание функционально неблагоприятных генотипов полиморфизма rs6165 + rs 6166 гена FSHR значительно увеличивает риск образования ПИЯ в 3,7 раза.

Доказано, что наиболее благоприятным/прогнозируемым генотипом для FSHR G> A rs6166 является генотип GG, тогда как генотип АA является рискованным. 